\title{
Serological Evidence of Henipavirus among Horses and Pigs in Zaria and Environs in Kaduna State, Nigeria
}

\author{
Olaolu T. Olufemi, ${ }^{1,2}$ Jarlath U. Umoh, ${ }^{2}$ Asabe A. Dzikwi, ${ }^{2}$ and Yemisi O. Olufemi ${ }^{3}$ \\ ${ }^{1}$ Department of Animal Production and Health, Faculty of Agriculture and Life Sciences, Federal University of Wukari, \\ Katsina-Ala Road, PMB 1020, Wukari, Taraba, Nigeria \\ ${ }^{2}$ Department of Veterinary Public Health and Preventive Medicine, Faculty of Veterinary Medicine, Ahmadu Bello University, \\ PMB 1045, Zaria, Kaduna State, Nigeria \\ ${ }^{3}$ School of Life Sciences, W/A1316 Microbiology, Queen's Medical Centre, University of Nottingham, Nottingham NG7 2UH, UK \\ Correspondence should be addressed to Olaolu T. Olufemi; toscoolufemi@gmail.com
}

Received 28 August 2015; Revised 8 October 2015; Accepted 13 October 2015

Academic Editor: Béla Dénes

Copyright ( 2015 Olaolu T. Olufemi et al. This is an open access article distributed under the Creative Commons Attribution License, which permits unrestricted use, distribution, and reproduction in any medium, provided the original work is properly cited.

Henipavirus is an emerging, zoonotic, and lethal RNA virus comprising Hendra virus ( $\mathrm{HeV}$ ) and Nipah virus (NiV), to which fruit bats are reservoir. Husbandry practices in Nigeria allow close contact between bat reservoir and animals susceptible to Henipavirus. This cross-sectional survey investigated antibodies reactive to Henipavirus $\mathrm{sG}$ antigen and associated risk factors in horses and pigs in Zaria, Nigeria. Using convenience sampling, 510 sera from horses $(n=200)$ and pigs $(n=310)$ were screened by an indirect Henipavirus enzyme-linked immunosorbent assay (ELISA) (CSIRO, Australia). Structured questionnaires were employed with questions on the demographics and management of the animals. Data were analysed using SPSS-17. 5. Seroprevalence was higher for horses managed intensively (21.1\%); used for sports (25.5\%); watered with pipe borne water (17.9\%); fed commercial feed (22.3\%); and fed in the pen (17.6\%). Seroprevalence was higher for pigs managed intensively (58.1\%); imported (69.5\%); watered with pipe-borne water $(31.3 \%)$; fed commercial feed $(57.4 \%)$; fed in the pen $(23.4 \%)$, and fed with feed prestored in a feed house (49.5\%). Horses $<5$ years and pigs $<6$ months had higher seroprevalences of $18.1 \%$ and $21.3 \%$, while the female horses and pigs had seroprevalences of $19.8 \%$ and $22.8 \%$, respectively. Exotic horses and pigs revealed $25.5 \%$ and $55 \%$ and horses in Igabi and pigs in Giwa revealed $24.7 \%$ and $70.2 \%$ seroprevalence, respectively $(P<0.05)$. There is a suggestive evidence of Henipavirus in horses and pigs in Zaria, Nigeria, with a huge public health implication. Local and exotic pigs and horses, pigs in Zaria and Sabon-Gari, and horses in Zaria, Sabon-Gari, and Kaduna North are associated with the seroprevalence of henipaviruses.

\section{Introduction}

In our world today, diseases are emerging and reemerging, among which is Henipavirus, a genus comprising two emerging zoonotic and highly lethal viruses (Hendra virus ( $\mathrm{HeV}$ ) and Nipah virus $(\mathrm{NiV})$ ) within the familyParamyxoviridae. Pteropid bats are the main reservoir for these closely related viruses causing highly fatal diseases in animals and human [1-4]. Bat paramyxoviruses cause versatile impact on livestock and human health leading to zoonotic infections and epizootics reportable to the World Organization for Animal Health (OIE) [5-8].

In 1994, a disease outbreak that affected thoroughbred race horses and human in Brisbane suburb of Hendra,
Queensland, was the first incidence of $\mathrm{HeV}$ [9]. There had been previous occurrence of these viruses in horses and also in a single human case (at Mackay, further north of Queensland) mistaken for equine morbillivirus [10, 11]; extensive survey revealed that Australian horses were not the likely source of infection [9, 12]. NiV first emerged in 1998-99 in Malaysia and Singapore where it caused acute febrile encephalitis in humans [13]. This major outbreak resulted in 265 human cases that claimed 105 lives in Malaysia [14]. In Singapore, it resulted in 11 cases and a death among abattoir workers who handled carcases of pigs imported from affected regions of Malaysia [15, 16].

Transmission cycles of $\mathrm{HeV}$ and $\mathrm{NiV}$ to man are unalike; $\mathrm{HeV}$ is first transmitted from bats to horses and then to man 
while $\mathrm{NiV}$ is first transmitted from bats to pigs then to man and also directly from bats to man as well as man to man [1720].

$\mathrm{HeV}$ and $\mathrm{NiV}$ are in the list of most deadly zoonotic viruses and have resulted in deaths or euthanasia of over 80 horses and four out of the seven humans known to be infected with $\mathrm{HeV}$ also died. There have been spill-over and recurrent outbreaks [16].

There is evidence of $\mathrm{HeV}$ and $\mathrm{NiV}$ in African bats, with other animals and birds holding switch predominance [7]. There is also evidence of anti-Henipavirus antibodies in West Africa [21], Annobón island in the Gulf of Guinea [22], and Cameroon. However, there are no relevant data available on Henipavirus in Nigeria.

Husbandry practices in developing countries allow close contact between bats and animals susceptible to Henipavirus as horses are tethered under trees overnight during recreation and polo. The practices in pig farming especially in villages allow close contact between bats and pigs. Deforestation makes bats leave their niche to urban settlements, bringing them in close contact with man, horses, and pigs. These pose a great risk to livestock farmers, veterinarians, and technicians performing their professional duties. The aim of the study was to detect the presence of Henipavirus in horses and pigs and to assess the risk factors for exposure to Henipavirus among horses and pigs in Zaria and its environs in northern Nigeria.

\section{Materials and Methods}

2.1. Sampling. Employing a nonrandom sampling technique, samples were collected with permission granted by local authorities (village/ward head(s)) and animal owners. Horses were sampled from Zaria, Sabon-Gari, Igabi, and Kaduna North while pigs were sampled from Zaria, Sabon-Gari, and Giwa. Following efficient restraint, $5 \mathrm{mls}$ of blood was aseptically collected from 310 pigs and 200 horses by anterior vena cava and jugular venepuncture, respectively. Blood samples collected in the field were transported in cool man box to the laboratory and clear sera from settled blood were harvested while unsettled blood was centrifuged at $3000 \mathrm{rpm}$ for 5 minutes before harvesting the sera. All sera were stored at $-20^{\circ} \mathrm{C}$ until needed for further analyses.

\subsection{Henipavirus Antibody Indirect Enzyme-Linked Immuno-} sorbent Assay ( $\mathrm{HeV} s \mathrm{G}$ iELISA). The ELISA used $50 \mu \mathrm{L} /$ well of Henipavirus sG antigen $(1: 3000)$ diluted in $0.05 \mathrm{M}$ carbonate-bicarbonate ELISA Coating Buffer ( $\mathrm{pH}$ 9.6) into a 96-well NUNC Maxisorp ELISA plate after which the plates were left stationary overnight at $4^{\circ} \mathrm{C}$. The plates were washed three times with Phosphate Buffered Saline Tween (PBST) and blocked for 30 minutes with $2 \%$ skimmed milk/Phosphate Buffered Saline Tween at $37^{\circ} \mathrm{C}$. Test and control sera were diluted $1: 100$ in $2 \%$ skimmed milk/PBS-T dilution buffer and $50 \mu \mathrm{l}$ was added to the plate and shaken for $1 \mathrm{hr}$ at $37^{\circ} \mathrm{C}$. Bound antibody was detected by using Protein A/G-Horse Radish Peroxidase conjugate (Pierce, Rockford, USA) and $3,3^{\prime}, 5,5^{\prime}$,-tetramethylbenzidine dihydrochloride (TMB) substrate (Sigma-Aldrich Pty. Ltd., Australia). Plates were read for absorbance using ELISA reader at an optical density of $450 \mathrm{~nm}$.

2.3. Questionnaire Survey. Data on the age, sex, breed, source of animal, source of feed and water, location, management system, and presence or absence of bat in environment of all animal sampled were recorded by observation and first-hand information from the animal owner/handler.

2.4. Statistical Analysis. Data generated were analysed using the Statistical Packages for Social Sciences (SPSS) Version 17.0. Chi square test was used where appropriate to test for association of variables (age, sex, breed, source, etc.) obtained from the questionnaires. Values of $P<0.05$ were considered significant.

\section{Results}

This study identified the occurrence of Henipavirus antibodies in pigs and horses sampled in Zaria and environs. Out of the 510 samples, 310 pigs and 200 horses, species-specific prevalence was $20 \%$ and $15.5 \%$ for pigs and horses, respectively.

3.1. Pig. A total of 197 and 113 pigs in this study fell within the age group $<6$ months and $\geq 6$ months, respectively (Table 2 ). Age group specific seroprevalence of $67.7 \%$ and $32.3 \%$ was obtained for pigs $<6$ months and $\geq 6$ months, respectively (Table 2). The sex specific seroprevalence was $17.6 \%$ and $22.8 \%$ for males and females, respectively (Table 2$)$. The breed of pigs included local $(n=216)$, exotic $(n=60)$, and cross breeds $(n=34)$ with antibody prevalence of $11.5 \%, 55 \%$, and $11.7 \%$, respectively. A statistically significant association existed between the breed of pigs and the seroprevalence $(P<$ 0.05) (Table 2).

Thirty-two (69.5\%) of the 46 imported pigs were seropositive while $30(11.3 \%)$ of the 264 locally sourced pigs were seropositive. The difference in the seroprevalence was statistically significant $(P<0.05)$ (Table 1$)$. Out of the study population, 155 pigs were sampled from Sabon-Gari, 108 from Zaria, and 47 from Giwa local government areas. A seroprevalence of $70.2 \%, 13.8 \%$, and $9 \%$ was recorded for Giwa, Zaria, and Sabon-Gari, respectively. There was statistically significant difference in seroprevalence by location of sampling (Table 1). Two hundred and eight of the pigs that were watered with well water had $14.4 \%$ seroprevalence while 102 watered with pipe-borne water had $31.3 \%$ seroprevalence. There was a statistically significant difference between prevalence of $\mathrm{HeV}$ antibodies $(P<0.05)$ and source of water (Table 1$)$. A total of 256 pigs were fed homemade feed and 54 were fed commercial feed. The feed type prevalence obtained was $12.1 \%$ and $57.4 \%$ for homemade and commercial feed, respectively. There was a statistically significant difference between prevalence and feed types $(P<0.05)$ (Table 1$)$. A prevalence of $15.2 \%$ and $23.4 \%$ was recorded for animals fed in the open and animals fed in the pen, respectively. Only ninety-one of the pigs sampled had their feed stored in a feed house before being fed to them; 48 pigs were fed prestored feed in the open 
TABLE 1: Risk factors associated with the prevalence of Henipavirus in pigs in Zaria and environs.

\begin{tabular}{|c|c|c|c|c|c|c|}
\hline Risk factor & Number & Number of seropositive animals (\%) & Chi, df & $P$ value & Odds ratio & $95 \%$ CI \\
\hline \multicolumn{7}{|c|}{ Management system } \\
\hline Intensive & 55 & $32(58.1)$ & \multirow{2}{*}{$60.92,1$} & \multirow{2}{*}{$<0.0001$} & \multirow[t]{2}{*}{10.43} & \multirow[t]{2}{*}{$5.41-20.14$} \\
\hline Semi-intensive & 255 & 30 (11.7) & & & & \\
\hline \multicolumn{7}{|l|}{ Source of animal } \\
\hline Imported & 46 & $32(69.5)$ & \multirow{2}{*}{$82.94,1$} & \multirow{2}{*}{$<0.0001$} & \multirow{2}{*}{17.83} & \multirow[t]{2}{*}{$8.56-37.25$} \\
\hline Locally sourced & 264 & $30(11.3)$ & & & & \\
\hline \multicolumn{7}{|l|}{ Source of water } \\
\hline Well & 208 & $30(14.4)$ & \multirow{2}{*}{$12.29,1$} & \multirow{2}{*}{0.0005} & \multirow[t]{2}{*}{0.37} & \multirow[t]{2}{*}{$0.21-0.65$} \\
\hline Pipe-borne & 102 & $32(31.3)$ & & & & \\
\hline \multicolumn{7}{|l|}{ Feed type } \\
\hline Homemade & 256 & $31(12.1)$ & \multirow{2}{*}{$57.19,1$} & \multirow{2}{*}{$<0.0001$} & \multirow[t]{2}{*}{0.10} & \multirow[t]{2}{*}{$0.05-0.20$} \\
\hline Commercial & 54 & $31(57.4)$ & & & & \\
\hline \multicolumn{7}{|l|}{ Feeding method } \\
\hline In the open & 131 & $20(15.2)$ & \multirow{2}{*}{$3.176,1$} & \multirow{2}{*}{0.0747} & \multirow[t]{2}{*}{0.59} & \multirow[t]{2}{*}{$0.33-1.06$} \\
\hline In the pen & 179 & $42(23.4)$ & & & & \\
\hline \multicolumn{7}{|l|}{ Feed storage } \\
\hline No storage & 171 & $11(6.4)$ & \multirow{3}{*}{$70.69,2$} & \multirow{3}{*}{$<0.0001$} & Ref. & \\
\hline Open & 48 & $6(12.5)$ & & & 0.48 & $0.17-1.38$ \\
\hline Feed house & 91 & $45(49.5)$ & & & 0.07 & $0.03-0.15$ \\
\hline \multicolumn{7}{|l|}{ Bat presence } \\
\hline No & 128 & $42(32.8)$ & \multirow[t]{2}{*}{$22.4,1$} & \multirow[t]{2}{*}{$<0.0001$} & \multirow[t]{2}{*}{0.253} & \multirow[t]{2}{*}{$0.140-0.458$} \\
\hline Yes & 182 & $20(10.9)$ & & & & \\
\hline Total & 310 & $62(20)$ & & & & \\
\hline
\end{tabular}

TABLE 2: Seroprevalence of antibodies reactive to Henipavirus sG antigen in pigs sampled in Zaria and environs based on age, sex, breed, and location.

\begin{tabular}{|c|c|c|c|c|c|c|}
\hline Variables & Number (\%) & Number of seropositive animals (\%) & $x^{2}$ & $P$ value & Odds ratio & $95 \% \mathrm{CI}$ \\
\hline \multicolumn{7}{|l|}{ Age } \\
\hline$<6$ months & 197 & $42(21.3)$ & 0.588 & 0.443 & 1.26 & $0.70-2.28$ \\
\hline$\geq 6$ months & 113 & $20(17.6)$ & & & & \\
\hline \multicolumn{7}{|l|}{ Sex } \\
\hline Male & 170 & $30(17.6)$ & $1.303,1$ & 0.2538 & 0.72 & $0.41-1.26$ \\
\hline Female & 140 & $32(22.8)$ & & & & \\
\hline \multicolumn{7}{|l|}{ Breed } \\
\hline Local & 216 & $25(11.5)$ & & & 0.11 & $0.06-0.21$ \\
\hline Exotic & 60 & $33(55)$ & 56.96 & $<0.0001$ & Ref. & \\
\hline Cross & 34 & $4(11.7)$ & & & 9.17 & $2.87-29.3$ \\
\hline \multicolumn{7}{|l|}{ Location } \\
\hline Zaria & 108 & $15(13.8)$ & $88.24,2$ & $<0.0001$ & 0.62 & $0.28-1.34$ \\
\hline Sabon-Gari & 155 & $14(9)$ & & & Ref & \\
\hline Giwa & 47 & $33(70.2)$ & & & 0.04 & $0.02-0.10$ \\
\hline Total & 310 & $62(20)$ & & & & \\
\hline
\end{tabular}

while 171 had no storage plan. The seroprevalence of $6.4 \%$, $12.5 \%$, and $49.5 \%$ was obtained from farm without storage, those who stored feed in the open, and those with a feed house, respectively. This difference between prevalence and feed storage was statistically significant $(P<0.05)$ (Table 1$)$. Thirty-two samples $(58.1 \%)$ from institutional farms managed intensively and 30 samples (11.7\%) from backyard farms managed semi-intensively had antibodies to Henipavirus antigen. There was statistically significant difference between seroprevalence and farm type/management practice $(P<$ 0.05 ) (Table 1). Only $10.9 \%$ of seropositives were obtained from pigs that had bats roost around/close to the farm while $32.8 \%$ of seropositives were obtained for pigs that did not have bats close to the farm. There was statistically significant association between prevalence and presence of bat around the farm $(P<0.05)$ (Table 1$)$. 
TABLE 3: Risk factors associated with the prevalence of Henipavirus in horses in Zaria and environs.

\begin{tabular}{|c|c|c|c|c|c|c|}
\hline Risk factor & Number & Number of seropositives (\%) & Chi, df & $P$ value & Odds ratio & $95 \% \mathrm{CI}$ \\
\hline \multicolumn{7}{|l|}{ Management system } \\
\hline Intensive & 128 & $27(21.1)$ & \multirow{2}{*}{$8.494,1$} & \multirow{2}{*}{0.0036} & \multirow[t]{2}{*}{4.50} & \multirow[t]{2}{*}{$1.50-14$} \\
\hline Semi-intensive & 72 & $4(5.5)$ & & & & \\
\hline \multicolumn{7}{|l|}{ Animal purpose } \\
\hline Sport & 106 & $27(25.5)$ & \multirow{3}{*}{17.172} & \multirow[t]{3}{*}{0.0002} & 6.2 & $1.4-27$ \\
\hline Leisure/traditional & 56 & $2(3.6)$ & & & 1.5 & $0.20-11.1$ \\
\hline Security & 38 & $2(5.3)$ & & & Ref. & \\
\hline \multicolumn{7}{|l|}{ Source of water } \\
\hline Well & 33 & $1(3)$ & \multirow[t]{2}{*}{$4.692,1$} & \multirow{2}{*}{0.0303} & \multirow[t]{2}{*}{0.14} & \multirow[t]{2}{*}{$0.02-1.1$} \\
\hline Pipe-borne & 167 & $30(17.9)$ & & & & \\
\hline \multicolumn{7}{|l|}{ Feed type } \\
\hline Homemade & 88 & $6(6.8)$ & \multirow{2}{*}{$9.043,1$} & \multirow{2}{*}{0.0026} & \multirow[t]{2}{*}{0.25} & \multirow[t]{2}{*}{$0.10-0.65$} \\
\hline Commercial & 112 & $25(22.3)$ & & & & \\
\hline \multicolumn{7}{|l|}{ Feeding method } \\
\hline In the open & 41 & $3(7.3)$ & \multirow{2}{*}{$2.637,1$} & \multirow{2}{*}{0.1044} & \multirow[t]{2}{*}{0.37} & \multirow[t]{2}{*}{$0.11-1.3$} \\
\hline In the pen & 159 & $28(17.6)$ & & & & \\
\hline \multicolumn{7}{|l|}{ Bat presence } \\
\hline No & 59 & $3(5.1)$ & \multirow[t]{2}{*}{22.4} & \multirow[t]{2}{*}{$<0.0085$} & \multirow[t]{2}{*}{4.63} & \multirow[t]{2}{*}{$1.35-15.9$} \\
\hline Yes & 141 & $28(19.8)$ & & & & \\
\hline Total & 200 & $31(15.5 \%)$ & & & & \\
\hline
\end{tabular}

3.2. Horses. Horses in the $<5$ yrs category had the highest seroprevalence of $18.1 \%$ compared to $5-15 \mathrm{yrs}$ and $>15 \mathrm{yrs}$ categories, both having seroprevalence of $15.2 \%$ and $14.8 \%$, respectively (Table 4 ). There was no significant association between the presence of antibodies to Henipavirus in horses sampled and the sex of the horse $(P<0.05)$. Female horses had a higher seroprevalence of $19.8 \%$ than the male horses, $11 \%$ (Table 4). Out of the 200 horses sampled 100, 98, and 2 where local, exotic, and cross breeds, respectively. Breed seroprevalence of $6 \%, 25 \%$, and $0 \%$ was obtained for local, exotic, and cross breed, respectively (Table 4 ).

Horses sampled were either imported $(n=106)$ or locally sourced $(n=94)$ with a seroprevalence of $23.5 \%$ and $6.3 \%$, respectively. The purpose for keeping horse in Zaria and environs was for sport $(n=106)$, leisure/tradition $(n=56)$, and security $(n=38)$. These categories had a seroprevalence of $25.4 \%, 3.5 \%$, and $5.2 \%$, respectively. The sources of water available for the horse were well $(n=33)$ and pipe-borne $(n=$ 167 ) water with seroprevalence of $3 \%$ and $17.9 \%$, respectively. There was a statistically significant difference in seropositivity between the sources of water consumed by the horse (Table 3). The location specific prevalence obtained was $6.3 \%$, $0 \%, 24.7 \%$, and $7.4 \%$ for Zaria, Sabon-Gari, Igabi, and Kaduna North, respectively (Table 3 ).

A total of 122 horses were fed commercial feed and 88 consumed homemade feed. There was a statistically significant difference in feed type with an individual prevalence of $6.8 \%$ and $22.1 \%$ for homemade and commercial feed, respectively $(P<0.05)$ (Table 3$)$. A seroprevalence of $7.3 \%$ and 17.6 was observed for horses fed in the open or in the pen in seropositivity between the feeding methods (Table 3). Only one horse had its feed stored in the open out of the 200 horses sampled. The management system practiced was semiintensive $(n=72)$ or intensive $(n=128)$. There was a statistically significant difference in seropositivity between the management practices. Semi-intensive practice had a seroprevalence of $5.5 \%$ while intensive practice had seroprevalence of $21 \%$ (Table 3 ).

A total of 141 horses had bats around the stable while 59 did not. The prevalence of antibodies was $19.8 \%$ for those with bats and $5.1 \%$ for those with no bats. There was a significant difference between the presence of bat and the presence of antibodies reactive to Henipavirus $(P<0.05)$ (Table 3$)$.

\section{Discussion}

The findings of this study showed that antibodies to Henipavirus are present in sera of horses and pigs in Zaria and environs with a prevalence of $15.5 \%$ and $20 \%$, respectively. This prevalence using $\mathrm{HeV}$ sG iELISA was lower than what was obtained by Hayman and his colleagues [23], who observed a prevalence of $39 \%$ and $22 \%$ for Nipah and Hendra, respectively, in E. helvum using Luminex binding assay. This study also investigated horses and pigs unlike most others who investigated only the major reservoir hosts. This indicates that infection with henipaviruses occur in Nigerian horses and pigs. These animals may constitute an important source of spread of the virus.

Breed et al. [22] also recorded a higher prevalence of $50 \%$ for Henipavirus in Papua New Guinea where 66 bats caught from three (3) different locations were screened. He also employed Luminex binding assay for initial screening after which they subjected the positive samples to viral neutralization test for confirmation. 
TABLE 4: Seroprevalence of antibodies reactive to Henipavirus sG antigen in horses sampled in Zaria and environs based on age, sex, breed, and location.

\begin{tabular}{|c|c|c|c|c|c|c|}
\hline Variables & Number (\%) & Number of seropositive animals (\%) & $x^{2}$ & $P$ value & Odds ratio & $95 \%$ CI \\
\hline \multicolumn{7}{|l|}{ Age } \\
\hline$<5$ years & 22 & $4(18.1)$ & 0.297 & 0.944 & 1.24 & $0.38-3.98$ \\
\hline $5-15$ years & 151 & $23(15.2)$ & & & Ref & \\
\hline$>15$ years & 27 & $4(14.8)$ & & & 0.97 & $0.31-3.06$ \\
\hline \multicolumn{7}{|l|}{ Sex } \\
\hline Male & 99 & $11(11)$ & $2.883,1$ & 0.0895 & 0.51 & $0.23-1.12$ \\
\hline Female & 101 & $20(19.8)$ & & & & \\
\hline \multicolumn{7}{|l|}{ Breed } \\
\hline Local & 100 & $6(6)$ & & & 0.19 & $0.07-0.48$ \\
\hline Exotic & 98 & $25(25.5)$ & ${ }^{*} 14.879$ & $<0.0001$ & Ref. & \\
\hline Cross & 2 & $0(0)$ & & & 0.58 & $0.03-12.42$ \\
\hline \multicolumn{7}{|l|}{ Location } \\
\hline Zaria & 63 & $4(6.3)$ & ${ }^{*} 12.461,3$ & 0.004 & 0.02 & $0.01-0.67$ \\
\hline Sabon-Gari & 9 & $0(0)$ & & & 0.18 & $0.01-2.81$ \\
\hline Igabi & 101 & $25(24.7)$ & & & Ref & \\
\hline Kaduna North & 27 & $2(7.4)$ & & & 0.24 & $0.05-1.10$ \\
\hline Total & 200 & $31(15.5)$ & & & & \\
\hline
\end{tabular}

${ }^{*}$ Fisher's exact test.

There is presently no commercial vaccine available for protection for henipaviruses in Africa and these animals are not routinely vaccinated against Henipavirus. Therefore, the demonstration of antibodies in sera of bats, horse, and pig is highly suggestive of natural exposure to the virus. The disparity in seroprevalences obtained between the two sampled animals (horses and pigs) might be due to the degree of susceptibility of each species.

Our finding on the age-specific seroprevalence is dissimilar with that of Peel et al. [21], where most adult bats yielded seropositives. The higher seroprevalence observed in younger animals (horse $<5$ years; $18.1 \%$ and pigs $<6$ months; $21.3 \%$ ), though not significant, is suggestive that young animals still have circulating maternal antibody. The female animals had a higher prevalence (Table 2 and Table 4 ) probably because more female animals are kept for reproductive purposes with just few males kept for servicing numerous females. This argues with the findings of Plowright et al [24] that observed that females are at significant higher risk of infection in flying fox than males especially during pregnancy and lactation. Female animals are retained in their numbers for longer periods than males making the virus more established in them due to infection and reinfection. In fact in this study area, more female horses are kept even for sporting purposes.

Exotic breeds probably had higher seroprevalence (horse, 25.5\%; pig, 55\%) because they were not immunologically strong to handle the infection as they are continuously embattled with new infections and environmental stress. The local breeds exhibited a hardy immune system.

Animals that are not indigenous are not immunologically potent to handle and curtail disease(s). This is probably the reason why imported horses (from Argentina) and pigs (from Holland) had higher prevalence than local breeds. The imported animals battle different stressors ranging from environmental stress to exposure to new infectious agents to which their immunity has not been pruned. It is possible that these imported animals actually came with Henipavirus infection since this virus is not being screened for at all.

Giwa and Igabi have sparsely distributed population with abundant trees and vegetation. This provides a natural and undisturbed habitat for the bat reservoir host and a probable continual dissemination of the virus in the environment.

Animals watered with pipe-borne water had a higher seroprevalence (pig, 31.4\%; horse, 17.9\%). This could be due to contamination by bats reservoir host, inefficient water treatment, fomite, and poor sanitary condition as pipe-borne water in this environment has its origin from dammed water bodies that bats drink from and also contaminate. The higher seroprevalence observed in animals fed commercial feed could be attributed to insufficient biosecurity practices in feed milling facility and also within the farm. This impaired biosecurity protocol allows the continuous spread of the virus within the farm and also to other farms especially during clearing sales. The bat reservoir host could also contaminate feed when stored in large quantities.

Animal fed in the pen had a higher seroprevalence, though not statistically significance. This could be because the bat reservoir host gains access to the pen thereby contaminating the feeding trough. Animals that had their feed stored in the feed house probably had the feed contaminated by the bat reservoir host which would normally gain access to feed houses.

The management system of the intermediate hosts may have contributed to the seropositivity recorded. Pigs and horses kept under intensive management are restricted and confined, giving room for close contact and cross contamination between animals. Pigs in intensive system are usually grouped depending on the programme on the farm (either 
breeding or fattening). In this study, all pigs from institutional farm were kept under intensive management system. This allowed for ease in spread of the virus through contact with discharges, body fluids, and even fomites.

Horses and pigs under intensive management may have had a high seroprevalence (horse, 21.1\%; pig, 58.1\%) due to contamination of feed and feeding trough by urine or faeces of bats that gain access to the farm. The virus is thus maintained more in intensive system as animals share the same feed and water source that could be contaminated by the reservoir host. This agrees with the work of Pulliam et al. [25].

Horses used for sport and sport related activities had a higher seroprevalence $(P<0.05)$. This group of animals is involved in various sporting events like polo allowing them close contact and cross contamination with numerous horses from different parts of the country. During this energy consuming events, horses are even tethered overnight under tree where fruit bats feed. This allows for a direct contamination of horse feed and water with urine, faeces, and feed droplets from bats.

The presence or absence of bat around the pen in horses and pigs yielded significant differences $(P<0.05)$ with higher prevalence found in horses that had bat around their pen (19.8\%) and higher prevalence among pigs that did not have bat roost around their pen. This is probably because of the gregarious and capricious feeding habit of pigs. This finding also further strengthens the ubiquitous nature of the reservoir host enhanced by flight such that even though not seen around, it could still transmit the virus to animals. Seroprevalence of Henipavirus among human populations, detecting and characterizing the virus, and examining its zoonotic potential are needed in the future.

\section{Conclusion}

There is an evidence of Henipavirus in Zaria, Kaduna state, Nigeria, with a species-specific seroprevalence of $15.5 \%$ and $20 \%$ of horses and pigs, respectively. Based on our results, the tested animals were likely infected with an unidentified Henipavirus. The prevalence has serious significant public health and economic implication on livestock owners, farmers, hunters, and professional health workers like veterinarians, veterinary assistants, and foresters.

Pigs managed under intensive management system, imported, given well water, fed homemade feed, and fed in the open without a feed storage plan are at the risk of Henipavirus infection. Horses managed under intensive system, used for sport and traditional purposes consume homemade feed, consume well water and feed in the open re at the risk of Henipavirus infection.

Demographically, local and exotic pigs and horses, pigs in Zaria and Sabon-Gari, and horses in Zaria, Sabon-Gari, and Kaduna North are associated with the seroprevalence of henipaviruses.

There is need for a nationwide surveillance to provide additional information on the epidemiology of Henipavirus in Nigerian horses and pigs. Pig and horse handlers should be enlightened on the importance of good sanitary and biosecurity measures.

\section{Conflict of Interests}

The authors declare that there is no conflict of interests regarding the publication of this paper.

\section{Acknowledgments}

The authors thank Professor Lin-Fa Wang, Gary Crameri, Christopher Morrissy, Jennifer Barr, and other members of the Diagnostic, Response and Surveillance Group at the CSIRO Australian Animal Health Laboratory who made the Antigen and other biologicals available for this work. They also thank Dr. Richard Edeh for his cooperation and assistance in sampling.

\section{References}

[1] K. Halpin, P. L. Young, H. E. Field, and J. S. Mackenzie, "Isolation of Hendra virus from pteropid bats: a natural reservoir of Hendra virus," Journal of General Virology, vol. 81, no. 8, pp. 1927-1932, 2000.

[2] B. T. Eaton, J. S. Mackenzie, and L. F. Wang, "Henipaviruses," in Fields Virology, D. M. Knipe, R. A. Lamb, S. E. Straus, P. M. Howley, M. A. Martin, and B. Roizman, Eds., pp. 1587-1600, Lippincott Williams \& Wilkins, Philadelphia, Pa, USA, 2007.

[3] K. Halpin, A. D. Hyatt, R. Fogarty et al., "Pteropid bats are confirmed as the reservoir hosts of henipaviruses: a comprehensive experimental study of virus transmission," The American Journal of Tropical Medicine and Hygiene, vol. 85, no. 5, pp. 946-951, 2011.

[4] L. McNabb, J. Barr, G. Crameri et al., "Henipavirus microsphere immuno-assays for detection of antibodies against Hendra virus," Paper 136, Uniformed Services University of the Health Sciences, 2014.

[5] J. F. Drexler, V. M. Corman, F. Gloza-Rausch et al., "Henipavirus RNA in African bats," PLoS ONE, vol. 4, no. 7, article e6367, 2009.

[6] S. K. P. Lau, P. C. Y. Woo, B. H. L. Wong et al., "Identification and complete genome analysis of three novel paramyxoviruses, Tuhoko virus 1, 2 and 3, in fruit bats from China," Virology, vol. 404, no. 1, pp. 106-116, 2010.

[7] J. F. Drexler, V. M. Corman, M. A. Müller et al., "Bats host major mammalian paramyxoviruses," Nature communications, vol. 3, article 796, 2012.

[8] K. S. Baker, S. Todd, G. A. Marsh et al., "Novel, potentially zoonotic paramyxoviruses from the African straw-colored fruit bat Eidolon helvum," Journal of Virology, vol. 87, no. 3, pp. 13481358, 2013.

[9] K. Murray, R. Rogers, L. Selvey et al., "A novel morbillivirus pneumonia of horses and its transmission to humans," Emerging Infectious Diseases, vol. 1, no. 1, pp. 31-33, 1995.

[10] K. Murray, P. Selleck, P. Hooper et al., "A morbillivirus that caused fatal disease in horses and humans," Science, vol. 268, no. 5207, pp. 94-97, 1995.

[11] J. D. O'Sullivan, A. M. Allworth, D. L. Paterson et al., "Fatal encephalitis due to a novel morbillivirus transmitted from horses," The Lancet, vol. 349, no. 9045, pp. 93-95, 1997.

[12] M. P. Ward, P. F. Black, A. J. Childs et al., "Negative findings from serological studies of equine morbillivirus in the Queensland horse population," Australian Veterinary Journal, vol. 74, no. 3, pp. 241-243, 1996. 
[13] K. B. Chua, K. J. Goh, K. T. Wong et al., "Fatal encephalitis due to Nipah virus among pig-farmers in Malaysia," The Lancet, vol. 354, no. 9186, pp. 1257-1259, 1999.

[14] K. B. Chua, "Nipah virus: A recently emergent deadly paramyxovirus," Science, vol. 288, no. 5470, pp. 1432-1435, 2000.

[15] N. I. Paton, Y. S. Leo, S. R. Zaki et al., "Outbreak of Nipah-virus infection among abattoir workers in Singapore," The Lancet, vol. 354, no. 9186, pp. 1253-1256, 1999.

[16] G. A. Marsh and L.-F. Wang, "Hendra and Nipah viruses: why are they so deadly?" Current Opinion in Virology, vol. 2, no. 3, pp. 242-247, 2012.

[17] E. S. Gurley, J. M. Montgomery, M. J. Hossain et al., "Person-toperson transmission of Nipah virus in a Bangladeshi community," Emerging Infectious Diseases, vol. 13, no. 7, pp. 1031-1037, 2007.

[18] N. Homaira, M. Rahman, M. J. Hossain et al., "Nipah virus outbreak with person-to-person transmission in a district of Bangladesh, 2007," Epidemiology and Infection, vol. 138, no. 11, pp. 1630-1636, 2010.

[19] S. P. Luby, M. J. Hossain, E. S. Gurley et al., "Recurrent zoonotic transmission of Nipah virus into humans, Bangladesh, 20012007," Emerging Infectious Diseases, vol. 15, no. 8, pp. 1229-1235, 2009.

[20] H. Field, K. Schaaf, N. Kung et al., "Hendra virus outbreak with novel clinical features, Australia," Emerging Infectious Diseases, vol. 16, no. 2, pp. 338-340, 2010.

[21] A. J. Peel, K. S. Baker, G. Crameri et al., "Henipavirus neutralising antibodies in an isolated island population of African fruit bats," PLoS ONE, vol. 7, no. 1, Article ID e30346, 2012.

[22] A. C. Breed, M. Yu, J. A. Barr, G. Crameri, C. M. Thalmann, and L.-F. Wang, "Prevalence of Henipavirus and rubulavirus antibodies in pteropid bats, Papua New Guinea," Emerging Infectious Diseases, vol. 16, no. 12, pp. 1997-1999, 2010.

[23] D. T. S. Hayman, R. Suu-Ire, A. C. Breed et al., "Evidence of Henipavirus infection in West African fruit bats," PLoS ONE, vol. 3, no. 7, article e2739, 2008.

[24] R. K. Plowright, H. E. Field, C. Smith et al., "Reproduction and nutritional stress are risk factors for Hendra virus infection in little red flying foxes (Pteropus scapulatus)," Proceedings of the Royal Society B: Biological Sciences, vol. 275, no. 1636, pp. 861869, 2008.

[25] J. R. C. Pulliam, J. H. Epstein, J. Dushoff et al., "Agricultural intensification, priming for persistence and the emergence of Nipah virus: a lethal bat-borne zoonosis," Journal of the Royal Society Interface, vol. 9, no. 66, pp. 89-101, 2012. 

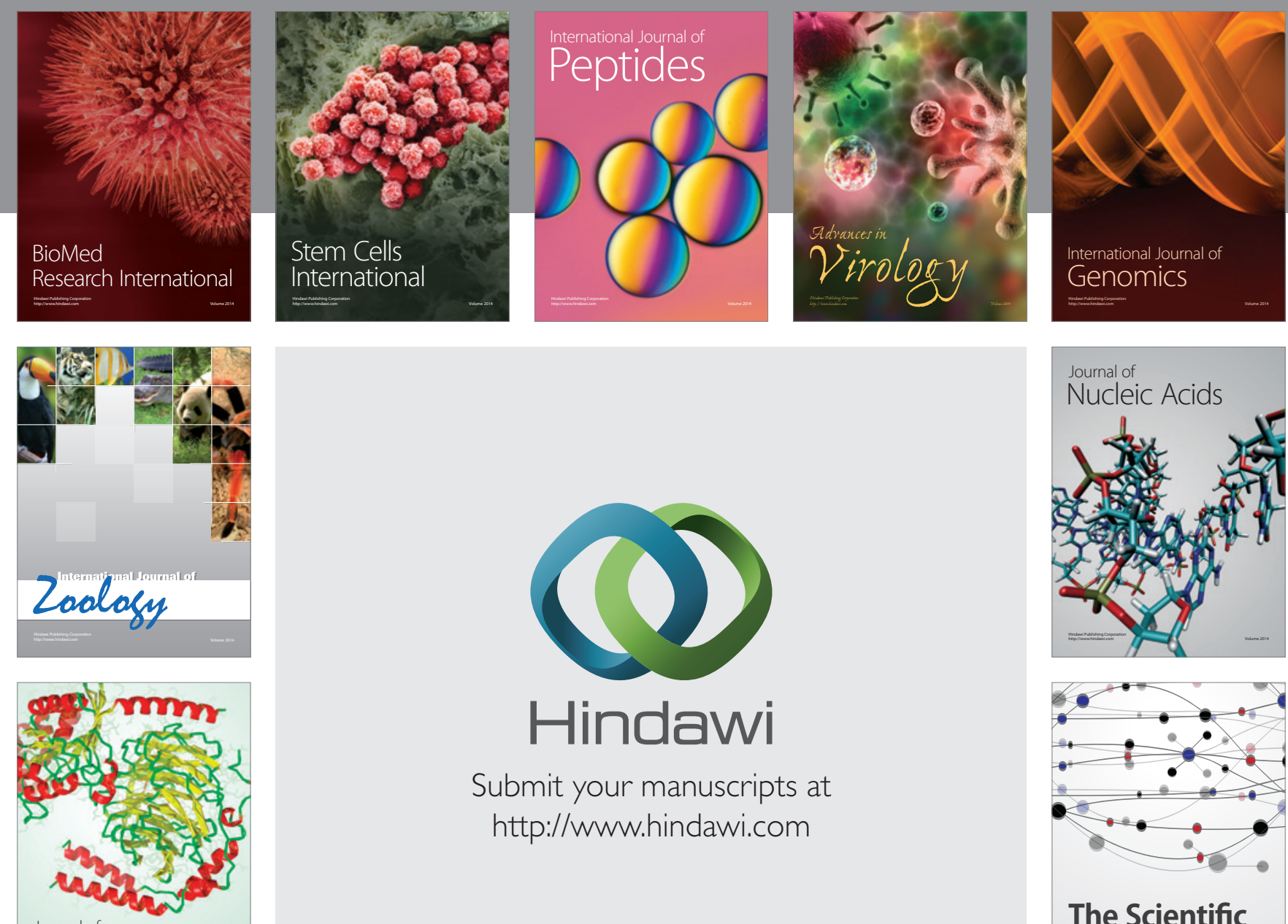

Submit your manuscripts at

http://www.hindawi.com

Journal of
Signal Transduction
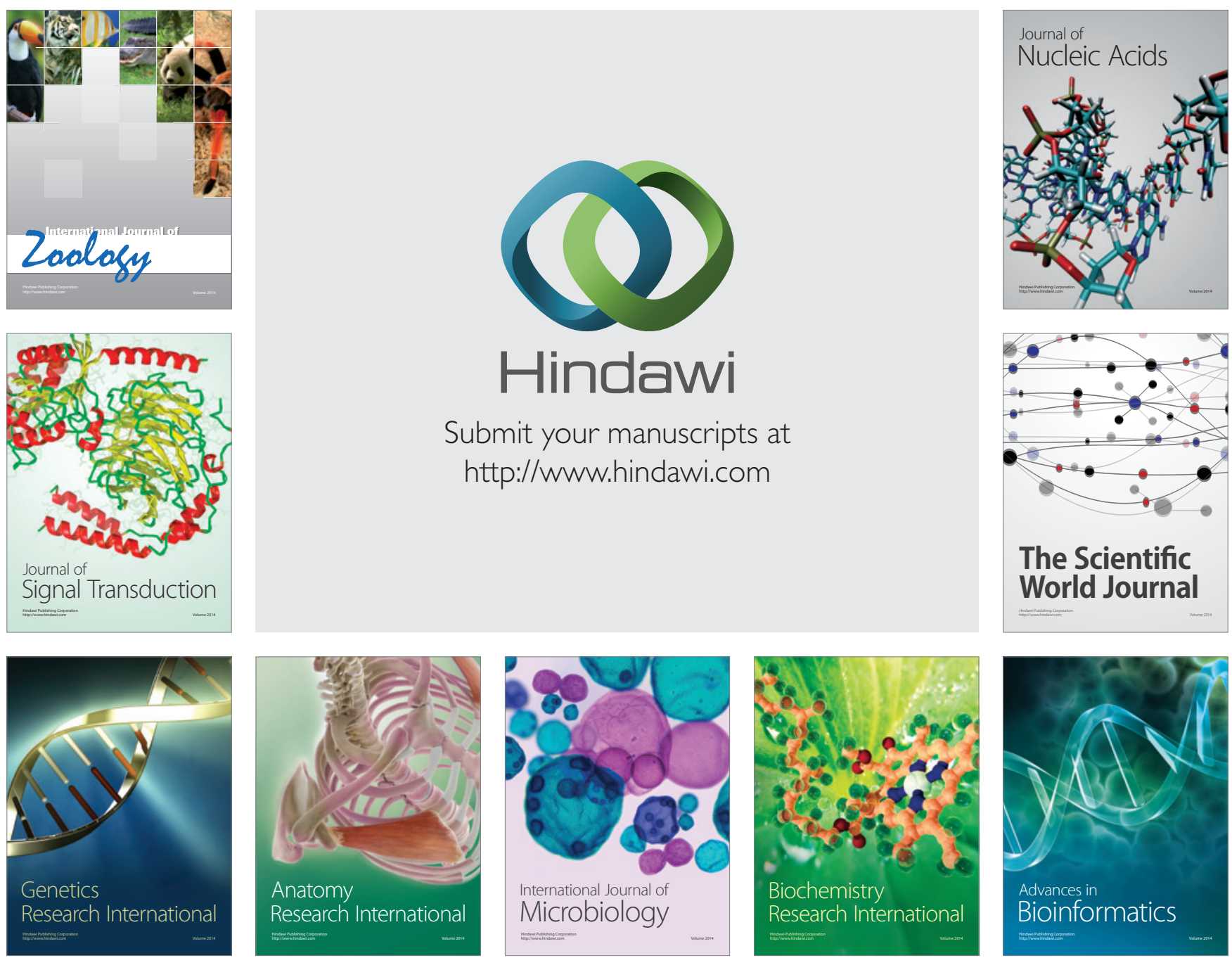

The Scientific World Journal
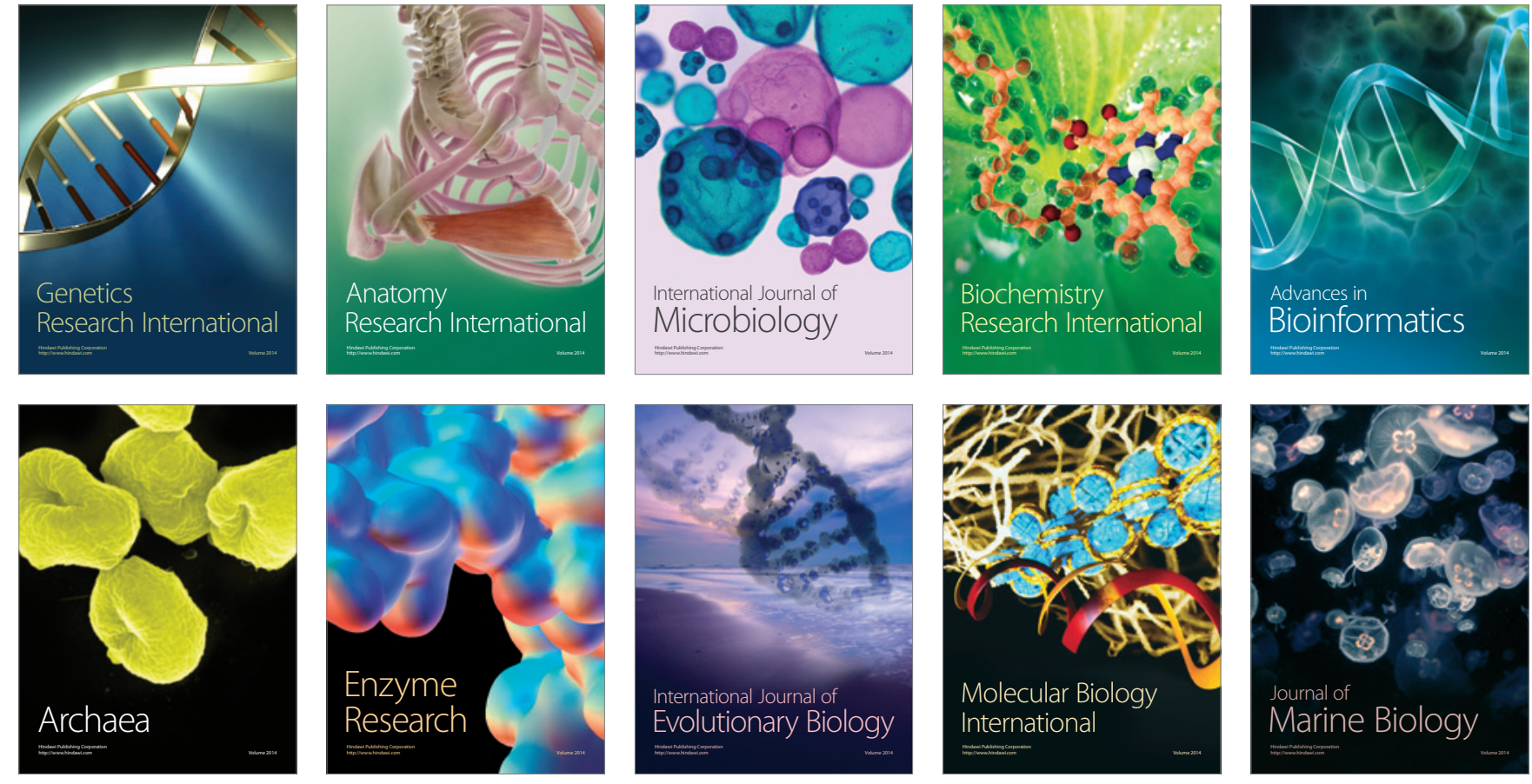